\section{KẾT LUẬN}

Tổn khuyết sau phẫu thuật ung thư khoang miệng thường có kích thước lớn, ảnh hưởng nhiêu đơn vị giải phẫu vùng mặt, đặt ra yêu cầu tạo hình phức tạp. Vạt đùi trước ngoài dạng chùm với nhiều ưu điểm trong phương pháp thiết kế và khả năng tạo hình đa cấu trúc là lựa chọn hàng đầu trong phục hồi giải phẫu và chức năng vùng khoang miệng.

\section{TÀI LIÊU THAM KHẢO}

1. Rivera C. Essentials of oral cancer. Int J Clin Exp Pathol. 2015;8(9):11884-11894. Published 2015 Sep 1.

2. Song Y.G, Chen G.Z and Song Y.L (1984). The free thigh flap: a newfree flap concept based on the septocutaneous artery. Br J Plast Surg, 37(2), 149-159

3. Koshima I, Yamamoto $H$, Hosoda $M$ et al (1993). Free combined composite flaps using the lateral circumflex femoral system for repair of massive defects of the head and neck regions: an introduction to the chimeric flap principle. Plast Reconstr Surg., 92(3), 411-420.

4. Ao M, Asagoe $K$, Maetat $M$ et al (1998). Combined anterior thigh flaps and vascularised fibular graft for reconstruction of massive composite oromandibular defects. The British Association of Plastic Surgeons, 51,350-355.

5. Huang W.C, Chen H.C, Jain V et al (2002). Reconstruction of throughand-through cheek defects involving the oral commissure, using chimeric flaps from the thigh lateral femoral circumflex system. Plast Reconstr Surg., 109(2), 433-441

6. Jose M. R.V, Pena A.A and Perez R.M (2008), Refining the Anterolateral Thigh Free Flap in Complex Orbitomaxillary Reconstructions. Plastic and reconstructive surgery, 121(2), 481-486.

7. Lawson B.R and Moreno M.A (2016). Head and Neck Reconstruction with Chimeric Anterolateral Thigh Free Flap: Indications, Outcomes, and Technical Considerations. Otolaryngology-Head and Neck Surgery, 154(1), 59-65.

8. Liu W.W, Yang A.K and Ou Y.D (2011). The harvesting and insetting of a chimeric anterolateral thigh flap to reconstruct through and through cheek defects. International Association of Oral and Maxillofacial Surgeons, 40(12), 1421-1423.

9. Wen C.L and Kuo C.Y (2015). One-stage through-and-through cheek, lips, and oral commissure reconstruction using a double-paddle peroneal chimeric flap: An innovative method. Head and Neck, 37(5), 662-669.

\title{
GIÁ TRI TIỂU CẦU VÀ BACH CẦU ĐỂ CHẨN ĐOÁN SỚM BỆNH SỐT XUẤT HUYẾT DENGUE Ở TRẺ EM
}

\section{TÓM TẮT}

Đă̆t vấn đề: Đếm tế bào máu toàn bộ là xét nghiệm cân thiết để chẩn đoán và theo dõi bệnh Sốt xuyết huyết dengue (SXHD). Mục tiêu: Xác định thời điểm thử máu thích hợp để có giá trị chẩn đoán SXHD cao nhất. Đối tượng và phương pháp: Đối tượng gồm 909 bệnh nhi nhập viện với chân đoán SXHD, từ 1-14 tuổi, được truy cứu từ bệnh án lưu trữ tại bênh viện An Giang trong chương trình nghiên cứu chủng ngừa SXHD của công ty Sanofi. Ghi nhânn kết quả đếm tế bào máu toàn bộ gồm tiểu cầu $(T C)$, Bạch cầu (BC), tế bào đa nhân trung tính (Neutro), tế bào lympho (lympho) và Dung tích hồng cầu (DTHC) vào ngày nhập viện. Kết quả: Có tất cả 909 bênh nhân được đếm tế bào máu toàn bộ, trong đó ngày 2 của bệnh có 65 , ngày 3 có 212 , ngày 4 có 312 , ngày 5 có 235 và ngày 6 có 68 bệnh nhân. TC giảm dần từ ngày 3 đến ngày 6 của bệnh. Vào ngày $4, \mathrm{TC}$ s $120.000 / \mathrm{mm}^{3}$ có độ nhạy và độ đặc hiệu lần lượt là

${ }^{1}$ Dai học Y Dược Cần Tho

${ }^{2}$ Bênh viên Sản Nhi An Giang

Chịu trách nhiệm chính: Nguyễn Ngọc Rạng

Email: nguyenngocrang@gmail.com

Ngày nhận bài: 16.12.2020

Ngày phản biên khoa học: 25.01.2021

Ngày duyệt bài: 2.2 .2021

\section{Nguyễn Ngọc Rạng ${ }^{1}$, Tôn Quang Chánh ${ }^{2}$}

$52 \%$ và $82 \%$. Với trị số $B C \leq 5000 / \mathrm{mm}^{3}$, đô nhạy và độ đặc hiệu vào ngày 3 của bệnh lân lượt là $54 \%$ và $74 \%$. Vào ngày 4 của bênh, đồ nhay và độ đăc hiêu của bệnh lần lượt là $57 \%$ và $61 \%$. Kết luận: Thờ điểm xét nghiệm đếm tế bào máu tốt nhất để chẩn đoán SXHD là vào ngày thứ 4 kể từ ngày bắt đâuu sốt.

Từ khóa: Sốt xuất huyết dengue, đếm tế bào máu toàn bộ, tiểu cầu, bạch câu.

\section{SUMMARY \\ THE VALUE OF PLATELET AND LEUCOCYTE COUNTS IN EARLY DIAGNOSIS OF DENGUE FEVER IN CHILDREN}

Background: A complete blood count (CBC) is an essential test for the diagnosis and monitoring of dengue hemorrhagic fever (DHF). Objective: To determine the proper time for doing the $C B C$ to make the most accurate diagnosis of DHF. Materials and methods: Subjects including 909 dengue patients with dengue $(+)$, from 1-14 years old, were extracted from the medical records stored at An Giang hospital in the dengue vaccine research program of Sanofi company. The CBC including platelets, white blood cells (WBC), percentage of neutrophils, percentage of lymphocytes and hematocrit was done on the day of admission. Results: A total of 909 patients had a CBC, of which day 2 had 65 , day 3 had 212 , day 4 had 312, day 5 had 235, and day 6 had 68 patients. The 
number of platelets gradually decreased between day 3 and day 6 of the disease. On day 4 , using the platelet cut-off of $\leq 120000 / \mathrm{mm}^{3}$, the sensitivity and specificity for the diagnosis of dengue fever were $52 \%$ and $82 \%$, respectively. Using the WBC cut-off of $\leq 5000 / \mathrm{mm}^{3}$, the sensitivity and specificity on day 3 were $54 \%$ and $74 \%$ respectively. On day 4 , the sensitivity and specificity for dengue fever were $57 \%$ and $61 \%$, respectively. Conclusion: The proper time for doing $\mathrm{CBC}$ (platelet, WBC) to make an accurate diagnosis of dengue fever is on day 4 of the onset of fever.

Keywords: Dengue fever, complete blood count, platelets, white blood cells

\section{I. ĐẶT VẤN ĐỀ}

Bệnh Sốt xuất huyết dengue (SXHD) là bệnh nhiễm khuẩn cấp tính gây ra do virus dengue gồm có 4 típ huyết thanh DEN-1, DEN-2, DEN-3 và $D E N-4$, được truyền bệnh chủ yếu do muỗi Aedes aegypti. Bệnh SXHD lưu hành quanh năm ở miền Nam Việt nam, cao điểm vào mùa mưa. Trong mùa dịch, chẩn đoán sớm bệnh SXHD thường dựa vào các triệu chứng lâm sàng gồm sốt cao, nhức đầu, ói mữa, niêm mạc mắt sung huyết, họng đỏ và dấu dây thắt $(+)[1],[8]$. Các dấu hiệu lâm sàng thường không điển hình, vì vậy thử máu để xem các trị số tiểu cầu (TC), bạch cầu $(B C)$ và dung tích hồng cầu (DTHC) rất cần thiết để chẩn đoán bệnh sớm. Trong những ngày đầu của bênh các chỉ số này thường chưa biến đổi nên dể chẩn đoán lầm với các bênh nhiễm siêu vi hoặc nhiễm trùng khác. Sự phân biệt SXHD với các bệnh khác giúp các thầy thuốc có các biện pháp xử lý sớm để làm giảm thương tật và tử vong.

Ngoài dấu hiệu dây thắt, xét nghiệm trị số $B C$ và TC có giá trị để chẩn đóan sớm bệnh SXHD [2-4], tuy nhiên nếu thử quá sớm trước ngày 3 của bênh có thể không phát hiên được, ngược lai nếu thử máu trễ khi bệnh nhân đã trở nặng hoặc vào sốc thì việc thử máu sẽ trở nên vố ích. Vì vậy việc thử máu vào thời điểm nào là thích hợp nhất để chẩn đoán bệnh SXHD rất là quan trọng.

Mục đích của nghiên cứu này là xác định thời điểm thử máu để có khả năng phát hiện bệnh SXHD cao nhất.

\section{II. ĐỐI TƯỢNG VÀ PHƯƠNG PHÁP NGHIÊN CỨU}

2.1 Đối tượng nghiên cứu. Gồm tất cả các hồ sơ bệnh nhân từ 1-14 tuổi được lưu trữ tại Khoa nhi, Bệnh viện Sản Nhi An Giang trong chương trình hợp tác nghiên cứu thuốc chủng ngừa SXHD với công ty Sanofi.

Tất cả các bênh nhân này nhập viện vào khoa Nhi bệnh viện An giang vào năm 2003 với chẩn đoán lâm sàng là SXHD. Tất cả các bệnh nhân này được đếm tế bào máu toàn bộ trên máy đếm tế bào tự động 18 chỉ số từ một đến nhiều lân, chỉ ghi nhận trị số $\mathrm{BC}$, tỉ lệ \% $\mathrm{BC}$ đa nhân trung tính, tỉ lệ \% $\mathrm{BC}$ lympho, $\mathrm{TC}$ và $\mathrm{DTHC}$ vào ngày nhập viện đầu tiên. Ngày bệnh được tính từ lúc bệnh nhân khởi sốt đến lúc nhập viện. Xét nghiệm để chẩn đoán xác định SXHD gồm phân lập virus cho các trường hợp nhập viện trước ngày 5 của bệnh và làm xét nghiệm Mac-Elisa (IgM và IgG) 2 lần cho tất cả các trường hợp. Cấy máu cho các trường hợp nghi ngờ mắc thương hàn hoặc nhiễm khuẩn huyết.

Tiêu chuấn loai trừ: Các hồ sơ bệnh nhân có kết quả cấy máu dương tính với thương hàn và các vi khuẩn gây nhiễm khuẩn huyết khác.

2.2 Phương pháp nghiên cứu. Hồi cứu mô tả, trích xuất tất cả các thông số của đếm tế bào máu toàn bộ từ hồ sơ theo ngày bệnh. Dựa vào kết quả xét nghiệm xác định SXHD khi ra viện, bệnh nhân được chia làm 2 nhóm: SXHD (+) và SXXHD (-)

Xử lý dữ liệu: Các số liệu được trình bày bằng trị trung bình và đô lệch chuẩn khi dữ liệu có phân phối chuẩn hoặc được trình bày bằng trị trung vị và khoảng tứ phân vị (interquatile range) khi không có phân phối chuẩn. Dùng phép kiểm $T$ cho các biến số có phân phối chuẩn hoặc phép kiểm Mann-Whitney nễu không có phẩn phối chuẩn. Dùng đường cong $R O C$ và chỉ số Youden để xác định điểm cắt của $\mathrm{TC}$ và $\mathrm{BC}$ tối ưu cho chẩn đoán SXHD. Tính AUC, độ nhạy và độ đặc hiệu theo trị tối ưu này. Các test thống kể khác biệt có ý nghĩa thống kê khi $p<0,05$. Dùng phần mềm SPSS 22.0 trong windows để xử lý thống kê.

\section{KẾT QUẢ NGHIÊN CỨU}

3.1 Đặc điểm chung. Tổng cộng có 909 trường hợp được chẩn đoán SXHD lúc nhập viện được đưa vào phân tích, trong đó có 567 trường hợp có kết quả dương tính và 342 trường hợp có kểt quả âm tính, đặc điểm chung của đối tượng nghiên cứu được trình bày trong bảng 1 .

Bảng 1. Đặc điểm chung của đối tượng nghiên cứu

\begin{tabular}{|c|c|c|c|}
\hline Đặc điểm & SXHD (-) $(\mathbf{n = 3 4 2 )}$ & SXHD (+) $(\mathbf{n = 5 6 7})$ & $\mathbf{P}$ \\
\hline Giới nam & $194(56,7 \%)$ & $280(49,4 \%)$ & 0,032 \\
\hline Tuối (năm) & $8,4 \pm 3,6$ & $8,4 \pm 3,2$ & 0,779 \\
\hline Bạch cấu x $1000 / \mathrm{mm}^{3}$ & $6,7 \pm 3,2$ & $6,0 \pm 3,3$ & 0,002 \\
\hline
\end{tabular}




\begin{tabular}{|c|c|c|c|}
\hline Neutrophile (\%) & $54,8 \pm 17,2$ & $57,3 \pm 15,4$ & 0,026 \\
\hline Lymphocyte (\%) & $37,9 \pm 16,0$ & $33,9 \pm 13,8$ & $<0,001$ \\
\hline Tiểu câu x1000/mm & $173 \pm 72$ & $102 \pm 63$ & $<0,001$ \\
\hline DTHC (\%) & $37,4 \pm 2,5$ & $38,8 \pm 3,0$ & $<0,001$ \\
\hline
\end{tabular}

Nhận xét: Không có sự khác biệt về giới và tuổi giữa 2 nhóm. Có sự khác biệt có ý nghĩa thống kê về số lượng BC, tỉ lệ neutrophil, tî̉ lệ lymphocyte, tiểu câu và DTHC giữa 2 nhóm

3.2 Số lượng bạch câu và tiểu câu theo ngày bệnh. Có tất cả 909 bệnh nhân được làm xét nghiệm đếm tế bào toàn bộ, trong đó ngày 2 (65), N3 (212); N4 (312); N5 (235) và N6 (68). Kết quả xét nghiệm TC theo ngày bệnh giữa 2 nhóm SXHD (+) và SXHD (-) được trình bày ở biểu đồ 1.

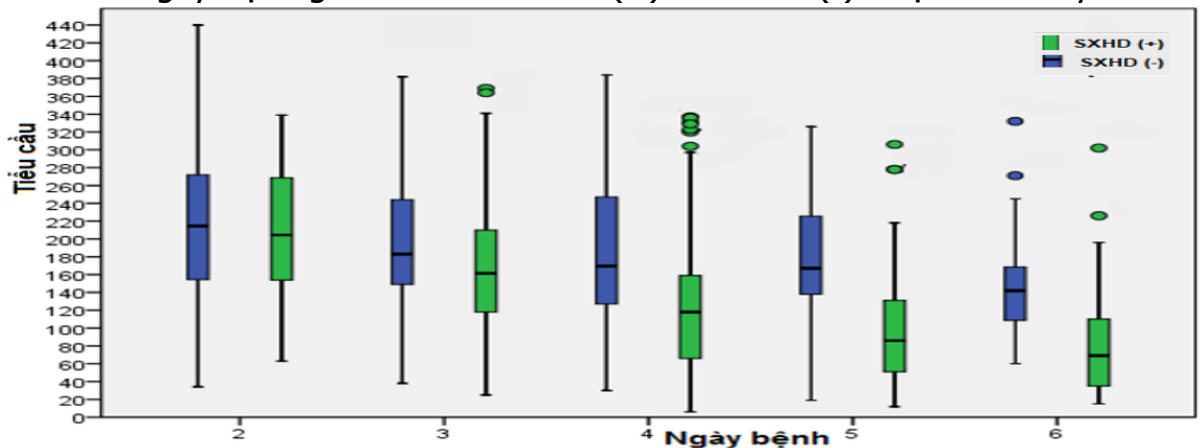

Biêu đồ 1. Sốlượng TC theo ngày bệnh giữa 2 nhóm SXHD (+) và SXHD (-)

Nhận xét: Số lượng TC trong nhóm SXHD (+) giảm dân từ N2 đến N6 của bệnh. Có sự khác biệt có ý nghĩa thống kê (phép kiểm Mann-Whitney) giữa 2 nhóm SXHD (+) và SXHD(-) theo ngày bệnh: N2 ( $p=0,995)$; N3 ( $p=0,002) ; N 4(p<0,001)$; N5 ( $p<0,001)$ và N6 ( $p<0,001)$.

Kết quả xét nghiệm BC theo ngày bệnh giữa 2 nhóm SXHD và SKXĐ được trình bày ở biểu đồ 2.

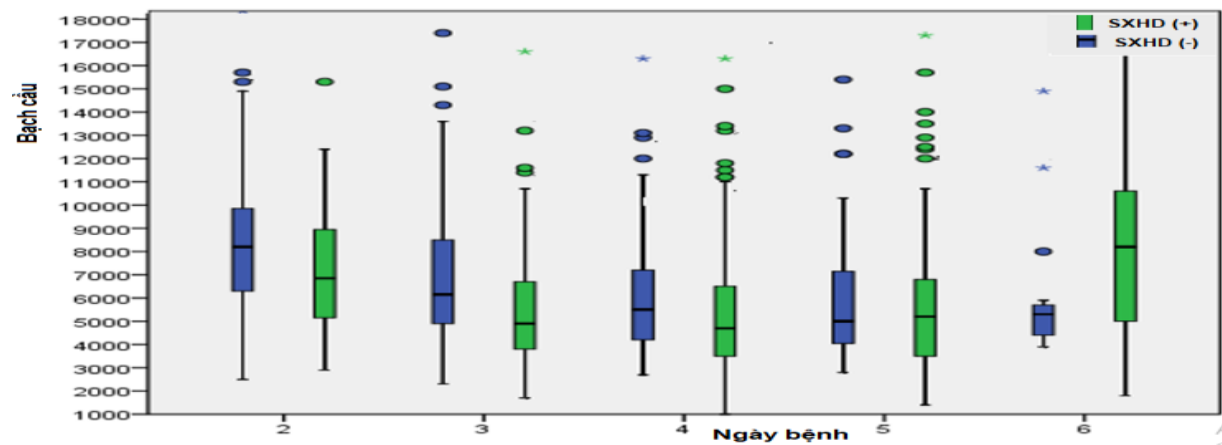

Biêu đồ 2. Số lượng BC theo ngày bệnh giữa 2 nhóm SXHD (+) và SXHD(-)

Nhânn xét: Số lượng BC trong nhóm SXHD giảm dần, có trị số thấp nhất vào N4 của bệnh. Có Sự khác biệt có ý nghĩa thống kê (phép kiểm Mann-Whitney) giữa 2 nhóm SXHD (+) và SXHD (-) từ N3 đến N6 của bệnh: N2 $(p=0,201)$; N3 $(p<0,001) ; N 4(p<0,001) ; N 5(p=0,035)$ và N6 $(p=0,022)$

\section{3 Độ nhạy và độ đặc hiệu theo ngày thử máu}

Chọn điểm cắt $\mathrm{TC} \leq 120.000 / \mathrm{mm}^{3}$ và $\mathrm{BC} \leq 5.000 / \mathrm{mm}^{3}$ là ngưỡng có sự phân biệt tối ưu giữa nhóm SXHD (+) và nhóm SXHD (-). Diện tích dưới đường cong (AUC), độ nhạy và độ đặc hiệu theo ngày thử máu với điểm cắt TC $\leq 120.000 / \mathrm{mm}^{3}$ được trình bày trong bảng 2 và 3 .

Bảng 2. Độ nhạy và độ đặc hiệu theo ngày thử máu với sốlướng TC $\leq 120.000 / \mathrm{mm}^{3}$

\begin{tabular}{|c|c|c|c|c|c|}
\hline $\mathrm{TC} \leq 120.000 / \mathrm{mm}^{3}$ & N2 $(n=65)$ & N3 $(n=212)$ & N4 $(n=312)$ & N5 $(n=235)$ & N6 $(n=68)$ \\
\hline AUC (KTC95\%) & $\begin{array}{c}0,50 \\
(0,36-0,64)\end{array}$ & $\begin{array}{c}0,63 \\
(0,56-0,70)\end{array}$ & $\begin{array}{c}0,74 \\
(0,69-0,79)\end{array}$ & $\begin{array}{c}0,82 \\
(0,76-0,86)\end{array}$ & $\begin{array}{c}0,81 \\
(0,70-0,90)\end{array}$ \\
\hline Độ nhạy & 0,11 & 0,26 & 0,52 & 0,68 & 0.83 \\
\hline Độ đặc hiệu & 0,82 & 0,92 & 0,82 & 0,79 & 0,68 \\
\hline
\end{tabular}

AUC: Diện tích dưới đường cong; KTC: Khoảng tin cậy; N: ngày thử máu; n: số trường hợp

Nhận xét: Trị TC giảm vào N2, N3 của bệnh có độ đặc hiệu cao, tuy nhiên độ nhạy thấp. Ttị TC giảm vào N4 của bệnh có độ nhạy và độ đặc hiệu chấp nhận được. 
Bảng 3. Độ nhạy và độ đặc hiệu theo ngày thử máu với số lượng $B C \leq 5.000 / \mathrm{mm}^{3}$

\begin{tabular}{|c|c|c|c|c|c|}
\hline BC $\leq \mathbf{5 . 0 0 0 / ~} \mathbf{~ m}^{\mathbf{3}}$ & $\mathbf{N 2}(\mathbf{n = 6 5})$ & $\mathbf{N 3} \mathbf{( n = 2 1 2 )}$ & $\mathbf{N 4} \mathbf{( n = 3 1 2 )}$ & $\mathbf{N 5} \mathbf{( N = 2 3 5 )}$ & $\mathbf{N 6} \mathbf{( n = 6 8 )}$ \\
\hline AUC (KTC 95\%) & 0,59 & 0,67 & 0,63 & 0,58 & 0,67 \\
& $(0,45-0,73)$ & $(0,59-0,74)$ & $(0,57-0,69)$ & $(0,50-0,64)$ & $(0,54-0,79)$ \\
\hline Độ nhạy & 0,18 & 0,54 & 0,57 & 0,47 & 0.24 \\
\hline Độ đặc hiệu & 0,92 & 0,74 & 0,61 & 0,58 & 0,59 \\
\hline
\end{tabular}

AUC: Diện tích dưới đường cong; KTC: Khoảng tin cậy; N: ngày thử máu; $\mathrm{n}$ : số trường hợp

Nhânn xét: Giảm BC máu vào N3 và N4 của bệnh có độ nhạy cao. Giảm BC có độ đặc hiệu vào N3 của bệnh cao hơn so với N4 của bệnh.

\section{BÀN LUÂ̂N}

Tiểu cầu $(\mathrm{TC})$ và bạch cầu $(\mathrm{BC})$ giảm là dấu hiệu đặc thù trong bệnh SXHD [6],[9] tuy nhiên nên thử máu vào ngày nào của bệnh để có độ nhạy và độ đặc hiệu tốt nhất, nếu thử sớm vào ngày $(\mathrm{N}) 1$ hoặc $\mathrm{N} 2$ của bệnh thì $\mathrm{BC}$ và $\mathrm{TC}$ chưa giảm, còn thử trễ vào N5, N6 thì bệnh nhân đã có nguy cơ vào sốc. Qua nghiên cứu 567 trường hợp SXHD (+) và 342 trường hợp SXHD (-) được thử máu từ N2 đến N6 của bệnh, chúng tôi nhận thấy số lượng TC giảm dần từ N3 và có trị số thấp nhất vào $\mathrm{N} 6$ của bệnh, điều này phù hợp với một nghiên cứu đoàn hệ về số lượng TC ở trẻ em và người lớn mắc SXHD tại BV Chợ Quán, các tác giả nhận thấy số lượng TC giảm thấp nhất từ N3 đến N6 của bệnh [5]. Chúng tôi chọn điểm cắt $\mathrm{TC}$ trong nghiên cứu này là $\leq 120.000 / \mathrm{mm}^{3}$, là trị số có độ nhạy và độ đặc hiệu cao nhất để phân biệt chẩn đoán giữa SXHD và SKXĐ. Theo nghiên cứu này, nếu cho thử máu vào N3 của bệnh thì độ nhạy chẩn đoán SXHD chỉ đạt $26 \%$, độ nhạy sẽ tăng lên gấp đôi (52\%) khi cho thử máu vào N4 của bệnh. Còn thử máu vào N5, N6 có độ nhạy cao hơn nhưng đã là giai đoạn trễ của bệnh. Tóm lại, thử máu vào ngày 4 của bệnh có khả năng phá t hiện dấu hiệu giảm TC tốt nhất.

Giảm BC thường gặp từ 50-90\% trong các ca SXHD [1]. Trong SXHD, số lượng BC lúc khởi phát bệnh có thể giảm hoặc tăng nhẹ tuy nhiên số lương $\mathrm{BC}$ luôn luôn giảm vào giai đoạn sắp hết sốt [6]. Nghiên cứu của Kalayanarooj và CS cho thây giảm $\mathrm{BC} \leq 5000 / \mathrm{mm}^{3}$ có độ nhạy là $90 \%$ và độ đặc hiệu là $60 \%$ trong chẩn đoán SXHD. Trong nghiên cứu của chúng tôi thì đô nhạy thấp hơn vì đối tượng nghiên cứu của chúng tôi bao gồm cả những trường hợp SXHD có sốc mà số lượng $\mathrm{BC}$ thường không giảm. Kết quả nghiên cứu này nhận thấy dấu hiệu giảm $\mathrm{BC}$ $\leq 5000 / \mathrm{mm}^{3}$ có độ nhạy tăng dần từ N2 $(18 \%)$, qua N3 $(54 \%)$ và cao nhất vào N4 $(57 \%)$ của bệnh, ngược lại độ đặc hiệu giảm dần từ N2 $(92 \%), N 3(74 \%)$ đến N4 của bênh $(61 \%)$. Vì vậy, thử máu vào ngày 3 và 4 của bệnh có khả năng phát hiện trị số giảm $B C$ tốt nhất.

Giảm $B C$ đa nhân trung tính và tăng $B C$ lympho cũng là triệu chứng đặc thù trong giai đoạn sắp hết sốt của SXHD [6],[7]. Tuy nhiên trong nghiên cứu này, chúng tôi nhận thấy tỉ lệ $\%$ của $\mathrm{BC}$ đa nhân trung tính tăng, còn tỉ lệ \% tế bào lympho giảm ở nhóm SXHD dương tính. Tuy nhiên tỉ lệ của $B C$ đa nhân trung tính và lympho còn thay đổi theo tuổi của bệnh nhi, vì vậy ít có giá trị trong chẩn đoán SXHD.

Một vấn đề đặt ra là thử máu càng trễ độ nhạy càng cao để phát hiện bệnh SXHD, tuy nhiên lúc này bệnh nhân đã trở nặng hoặc đã vào sốc thì việc thử máu sẽ không còn giá trị để theo dõi bệnh. Qua nghiên cứu này chúng tôi nhân thấy có $5 / 474$ trường hợp sốc xảy ra vào ngày 3 của bệnh, chiếm tỉ lệ khoảng $1 \%$ là không nhiều, tuy nhiên để đề phòng các trường hợp vào sốc sớm nên cho thử máu sớm vào N3 của bệnh ở những bệnh nhân đã có dấu hiệu cảnh báo.

\section{KẾT LUẬN}

Số lượng TC giảm dần từ N3 đến N6 của bệnh. Số lượng $\mathrm{BC}$ giảm thấp nhất vào N4 của bệnh. Độ nhạy và độ đặc hiệu của giảm TC ( $\leq$ $120.000 / \mathrm{mm}^{3}$ ) tốt nhất để chẩn đoán SXHD xảy ra vào N4 của bệnh. Độ nhạy và độ đặc hiệu của giảm $\mathrm{BC}\left(\leq 5.000 / \mathrm{mm}^{3}\right)$ tổt nhất để chẩn đoán SXHD xảy ra vào N3 và N4 của bệnh.

Kiến nghị: Để chẩn đoán bệnh SXHD thây thuốc nên cho bệnh nhân thử máu vào đầu ngày thứ 4 của bệnh kể từ ngày bắt đầu sốt, thời điểm mà dấu hiệu giảm BC và/hoặc giảm TC có độ nhạy và độ đặc hiệu tương đối cao, tuy nhiên nên thử máu vào N3 ở những bệnh nhân đã có dấu hiệu nặng hoặc dấu hiệu cảnh báo của SXHD.

\section{TÀI LIÊU THAM KHẢO}

1. George R. and Lum C.S (1997) Clinical spectrum of dengue infection. In Dengue and Dengue Hemorrhagic Fever. Editer by D.J. Gubler and G. Kano, Cab International, U.K. pp:89-115.

2. Potts JA, Rothman AL. (2008) Clinical and laboratory features that distinguish dengue from other febrile illnesses in endemic populations. Trop Med Int Health.;13(11):1328-40. 
3. Kalayanarooj S, Vaughn DW, Nimmannitya S, et al. (1997) Early clinical and laboratory indicators of acute dengue illness. J Infect Dis. 176(2): 313-21.

4. Kalayanarooj $S$ Nimmannitya $S$, Suntayakorn S, et al. (1999) Can Doctors Make an Accurate Diagnosis of Dengue Infections at an Early Stage? Dengue Bulletin Volume 23.

5. Dinh The T, Le Thi Thu T, Nguyen Minh D, et al. (2012) Clinical features of dengue in a large vietnamese cohort: intrinsically lower platelet counts and greater risk for bleeding in adults than children. PLoS Negl Trop Dis. 6(6):e1679.

6. WHO. Dengue haemorrhagic fever. Diagnosis, treatment, prevention and control. $2^{\text {nd }}$ Edition (1997). WHO Geneva, pp. 12-23

7. Nimmannitya S. (1997) Dengue hemorrhagic fever: diagnosis anh management, in Dengue and Dengue hemorragic fever, edited by Gubler D.J and Kuno G, Cab International, UK, pp. 133-145.

8. Phuong CX, Nhan NT, Kneen R, et al. (2004). Clinical diagnosis and assessment of severity of confirmed dengue infections in Vietnamese children: is the world health organization classification system helpful? Am J Trop Med Hyg.70(2): 172-9.

9. Gubler DJ. (1998) Dengue and dengue hemorrhagic fever. Clin Microbiol Rev.;11(3):48096. Review

\section{SO SÁNH TÁC DUUNG TRÊN TUẦN HOÀN VÀ CÁC TÁC DỤNG KHÔNG MONG CỦA ONDANSETRON VỚI DEXAMETHASON HOĂC METOCLOPRAMID ĐỂ DỰ PHÒNG NÔN, BUỒN NÔN TRONG VÀ SAU MỔ LẤY THAI}

\section{TÓM TẮT}

Mục tiêu: So sánh tác dụng trên tuần hoàn và các tác dụng không mong muốn của Ondansetron với Dexamethason hoặc Metoclopramid để dự phòng nôn, buồn nôn trong và sau mổ lấy thai. Đối tượng, phương pháp nghiên cứu: Nghiên cứu được tiến hành trên 90 sản phụ ASA I-II (20 - 41 tuổi), có chì định mổ lấy thai, vô cảm bằng gây tê tủy sống, tại khoa Gây mê hồi sức, Bệnh viện phụ sản Hà Nội từ tháng 1 đến tháng 7 năm 2020. Các sản phụ được phân loại ngẫu nhiên thành ba nhóm bằng nhau: Nhóm $O$ được tiêm tĩnh mạch $8 \mathrm{mg}$ Ondansetron, nhóm $\mathrm{D}$ được tiêm tĩnh mạch $8 \mathrm{mg}$ Dexamethason, nhóm $M$ được tiêm tĩnh mạch $10 \mathrm{mg}$ Metoclopramid. Các tác dụng không mong muốn được đánh giá liên tục trong và 24 giờ đâu sau mổ. Kết quả: Tỷ lệ tụt huyết áp của các bệnh nhân ở nhóm Ondansetron là $36,7 \%$; của nhóm Dexamethasone là $56,7 \%$ và của nhóm Metoclopramide là 53,3\%, khác biệt có ý nghĩa thống kê $(p<0,05)$. Tỷ ngứa của ba nhóm lần lượt là: $36,7 \%$ so với $56,7 \%$ và $43,3 \%$, khác biệt không có ý nghĩa thống kê $(p>0,05)$. Không gặp trường hợp nào bị đau thượng vị, rối loạn nhịp tim hoặc bị hội chứng ngoại tháp... Kểt luận: Tỷ lệ tụt huyết áp của các bệnh nhân ở nhóm Ondansetron thấp hơn có ý nghĩa thống kê so với nhóm Dexamethason hoặc nhóm Metoclopramid với $p<0,05$. Tỷ lệ các tác dụng không mong muốn khác như: ngứa, đau thượng vị... không có sự khác biệt giữa ba nhóm. Không gặp trường hợp nào bị rối loạn nhịp tim hoặc bị hội chứng ngoại tháp.

\footnotetext{
${ }^{1}$ Trường Đại họ Y HN

${ }^{2}$ Bênh viên Đa khoa tỉnh Vînh Phúc

Chịu trách nhiệm chính: Nguyễn Đức Lam

Email: lamgmhs75@gmail.com

Ngày nhận bài: 21.12.2020

Ngày phản biện khoa họ: 29.01.2021

Ngày duyệt bài: 2.2.2021
}

\section{Nguyễn Đức Lam ${ }^{1}$, Vũ Văn Hiệp ${ }^{2}$}

Tư khóa: Gây tê tủy sống, Ondansetron, Dexamethason, Metoclopramid, mổ lấy thai.

\section{SUMMARY \\ THE COMPARISON OF THE CIRCULATION EFFECTS AND SIDE EFFECTS OF \\ ONDANSETRON WITH DEXAMETHASONE OR METOCLOPRAMIDE TO PREVENT VOMITING, NAUSEA DURING AND AFTER CESAREAN SECTION}

Objective: To compare the effects on circulation and side effects of Ondansetron with Dexamethasone or Metoclopramide to prevent vomiting, nausea during and after cesarean section. Methods: This study was conducted on 90 ASA I-II women (20 - 41 years old) indicated cesarean section with spinal anesthesia, at the Department of Anesthesiology, Hanoi Obstetrics and Gynecology Hospital from January to July 2020. The patients were randomly divided into three similar groups: Group $\mathrm{O}$ was administered intravenously $8 \mathrm{mg}$ of Ondansetron, group $D$ with $8 \mathrm{mg}$ of Dexamethasone and group $M$ with $10 \mathrm{mg}$ of Metoclopramide. The side effects were recorded continuously during surgery and the first 24 hours after surgery. Results: The rate of hypotension in the Ondansetron group was $36.7 \%$; in the Dexamethasone group was $56.7 \%$ and in the Metoclopramide group was $53.3 \%$, the difference was statistically significant ( $p<0.05$ ). The pruritus rates of the three groups were $36.7 \%, 56.7 \%$ and $43.3 \%$, respectively, the difference was not statistically significant ( $p>0.05)$. No cases of epigastric pain, arrhythmia or extrapyramidal syndrome ...

Conclusion: The rate of hypotension in the Ondansetron group was statistically significantly lower than in the Dexamethasone group or the Metoclopramide group with $p<0.05$. The rates of other side effects such as: pruritus, epigastric pain... did not differ between the three groups. There was no case of arrhythmia or extrapyramidal syndrome. 